\title{
Review Article \\ Sex Hormones and Their Receptors Regulate Liver Energy Homeostasis
}

\author{
Minqian Shen and Haifei Shi \\ Cell, Molecular, and Structural Biology, Department of Biology, Miami University, 700 E. High Street, Oxford, OH 45056, USA \\ Correspondence should be addressed to Haifei Shi; shih@miamioh.edu
}

Received 11 May 2015; Revised 5 August 2015; Accepted 9 August 2015

Academic Editor: Małgorzata Kotula-Balak

Copyright ( $) 2015$ M. Shen and H. Shi. This is an open access article distributed under the Creative Commons Attribution License, which permits unrestricted use, distribution, and reproduction in any medium, provided the original work is properly cited.

\begin{abstract}
The liver is one of the most essential organs involved in the regulation of energy homeostasis. Hepatic steatosis, a major manifestation of metabolic syndrome, is associated with imbalance between lipid formation and breakdown, glucose production and catabolism, and cholesterol synthesis and secretion. Epidemiological studies show sex difference in the prevalence in fatty liver disease and suggest that sex hormones may play vital roles in regulating hepatic steatosis. In this review, we summarize current literature and discuss the role of estrogens and androgens and the mechanisms through which estrogen receptors and androgen receptors regulate lipid and glucose metabolism in the liver. In females, estradiol regulates liver metabolism via estrogen receptors by decreasing lipogenesis, gluconeogenesis, and fatty acid uptake, while enhancing lipolysis, cholesterol secretion, and glucose catabolism. In males, testosterone works via androgen receptors to increase insulin receptor expression and glycogen synthesis, decrease glucose uptake and lipogenesis, and promote cholesterol storage in the liver. These recent integrated concepts suggest that sex hormone receptors could be potential promising targets for the prevention of hepatic steatosis.
\end{abstract}

\section{Introduction}

Obesity rapidly becomes a worldwide epidemic disease with increased risk of cardiovascular diseases, type 2 diabetes mellitus, and metabolic syndrome [1]. Metabolic syndrome is characterized by increased visceral adiposity, hyperlipidemia, insulin resistance, and hypertension [2]. The liver is the largest visceral organ for maintaining homeostasis in glucose, lipid, and protein. Hepatic steatosis is characterized by massive fat accumulation in the liver and thus is strongly related to several features of metabolic syndrome, including hyperlipidemia and insulin resistance [3]. Indeed, reduction or loss of insulin action in the liver leads to abnormally increased hepatic gluconeogenesis, glucose production, and lipogenesis, as well as decreased insulin clearance, hepatic glucose uptake, and lipolysis, consequently resulting in dyslipidemia [4].

Age and sex are physiologic factors that have strong association with the prevalence and features of metabolic syndrome. The state of estrogen deficiency as seen in postmenopausal women and the state of androgen deficiency as seen in aging men predispose older population to the metabolic syndrome and associated diabetes and cardiovascular diseases, indicating that sex hormones play important roles in regulating energy metabolism $[5,6]$. Nonalcoholic fatty liver disease (NAFLD) disproportionally affects people with obesity, diabetes with insulin resistance, and dyslipidemia [7-9]. The prevalence of NAFLD varies among ethnicities, with the highest prevalence in Hispanics, correlated with the high prevalence of obesity and insulin resistance in this ethnic group, compared to whites and blacks [10]. Similar to the incidence of metabolic syndrome, the frequency of NAFLD varies between genders, with greater prevalence in men than in women among whites ( $42 \%$ in white men versus $24 \%$ in white women) but not in other ethnicities [10]. This is consistent with another epidemiology study showing that the rate of NAFLD is a little higher in men than in women with all ethnicities combined [7]. Interestingly, NAFLD is twice as common in postmenopausal women as in premenopausal women whose estrogen levels are higher than postmenopausal women $[7,11]$, which suggests the protective role of estrogens in NAFLD $[12,13]$. 
In general, androgens are considered as hormones of the male sex due to their masculinizing effects and their roles in regulating male sexual behavior, whereas estrogens are considered as hormones of the female sex due to their roles in regulating female reproductive physiology and behaviors, although all sex hormones are present in both males and females, albeit at different levels between these two sexes. The most important biologically relevant forms of estrogens and androgens in humans are estradiol (E2) and testosterone, respectively. Understanding of how estrogens and androgens regulate energy metabolism via their receptors may shed light on potential pharmaceutical applications. In the present review, we discuss the roles of estrogens and androgens in regulating liver glucose and lipid homeostasis in rodents and humans. We also deliberate the distinct, important effects of estrogen receptors (ERs) and androgen receptors (ARs) on the regulation of liver metabolism.

\section{The Role of Estrogens in Regulating Liver Energy Homeostasis}

2.1. Estrogen Signaling. In both males and females, E2 is derived from the aromatization of testosterone. In premenopausal women, E2 is mainly synthesized from cholesterol in the ovaries, with E2 concentration being approximately 5 times higher than that in men, while in postmenopausal women E2 is primarily converted from testosterone by aromatase in peripheral tissues, such as adipose tissue, adrenal glands, bones, vascular endothelium, and smooth muscle [14], with E2 concentration being similar compared with men (http://www.hemingways.org/GIDinfo/ hrt_ref.htm).

Estrogens act on ERs, including classic nuclear receptors ER- $\alpha$ and ER- $\beta$, and membrane-bound receptors, including G protein-coupled ER (GPER, also known as GPR 30) and membrane-associated ER- $\alpha$ and ER- $\beta$ variants [15]. All these nuclear and membrane ER subtypes are expressed in the livers of male and female humans and rodents, but at a lower level compared with reproductive organs such as uterus, prostate, testis, ovary, and breast [16-18]. ER- $\beta$ is less abundant in liver cells than ER- $\alpha[19,20]$ and GPER (unpublished observation).

One study by Lax et al. determines levels of ERs in male and female rat livers and reports that the levels of nuclear ERs are not sex dependent but are age dependent, as levels of ERs are similar between male and female rats and vary with the course of life in a comparable manner in males and females [21]. Specifically, levels of ERs in the liver of both male and female rats are the highest during the perinatal period, decline till the onset of puberty, and increase to reach postpubertal peak. Additionally, levels of ERs are maintained as a stable level across the estrous cycles of female rats [21]. Consistently, Eisenfeld group has reported that ER concentration in the rat liver increases evidently at puberty [22]. Ovariectomy $(\mathrm{OVX})$, a procedure that removes ovaries and thus majority of endogenous estrogens, is a suitable preclinical model to study postmenopausal diseases. Liver ER- $\alpha$ expression does not change following OVX; however, it significantly increases by E2 treatment at a superphysiological level in rats with OVX, higher than sham-operated rats with intact ovaries and normal levels of endogenous estrogens [23]. These studies indicate that ER- $\alpha$ expression in the liver is similar between gonad intact males and females and remains stable in postmenopausal females but could increase following hormone replacement therapy or during puberty. There is no available literature showing changes of expression of ER- $\beta$ and GPER during menstrual period or postmenopausal stage, and these questions remain unknown.

Males also express ERs in the liver, and aromatase metabolizes androgens to generate E2 and other estrogen metabolites locally in many target tissues. A growing body of evidence suggests that estrogens also have important metabolic functions in males. The aromatization of testosterone to E2 is beneficial for preventing intra-abdominal adiposity in men, demonstrated by a clinical study showing increased intraabdominal fat in men by reduced estrogens due to aromatase inhibition [24]. The effects of estrogens on male and female reproductive organs have been extensively studied, but the beneficial effects of estrogens in nonclassical endocrine targets including the liver are less appreciated. We will discuss how hepatic estrogen signaling via ERs regulates metabolism in male and female animal and human models.

Upon estrogen binding, classic estrogen nuclear receptors ER- $\alpha$ and ER- $\beta$ form homo- or heterodimers and bind to estrogen response element (ERE) in target gene promoters or to other transcription factors, such as activator protein-1 (AP1) and stimulating protein-1 [25], to induce expression of target genes. The genomic action following E2-ER binding varies as the level of sex hormone changes. Specifically, the transcriptional activity of ER- $\alpha$ alters during the 4-day estrous cycle, demonstrated by using ERE-luciferase reporter mice which have luciferase reporter controlled by activated ERs. The peak of the transcriptional activity of ER- $\alpha$ in the liver occurs in proestrus [26], indicating dynamics of ER- $\alpha$ transcriptional activity that is possibly modulated by different concentration of estrogens [27]. These findings suggest that liver ER- $\alpha$ could recognize the changes in circulating E2 levels and response to reproductive cues during transition of different stages of the estrous cycles and select appropriate genetic programs to adapt the hepatic metabolism to the energy requirements of each stage. Thus, the hepatic ER- $\alpha$ could serve as a peripheral coordinator of energy homeostasis. ER$\alpha$ also exists in the form of membrane-associated receptor. There are many lines of evidence showing that the full length ER- $\alpha$ and truncated ER- $\alpha$ may exert actions via nongenomic signaling which is faster than the classic genomic signaling. Such nongenomic signaling usually involves activation of intracellular second messenger systems, such as protein kinase A (PKA), protein kinase $\mathrm{C}$, and mitogen-activated protein kinase (MAPK)/extracellular signal-regulated protein kinase (ERK) [28-30]. GPER is structurally unrelated to ER- $\alpha$ and ER- $\beta$ and is a seven-transmembrane domain G protein-coupled receptor located at the cell membrane and endoplasmic reticulum membrane. GPER is reported to rapidly activate different nongenomic estrogen signaling pathways, including PKA, MAPK/ERK, and phosphoinositide 3-kinase (PI3K) [31] (Figure 1). 


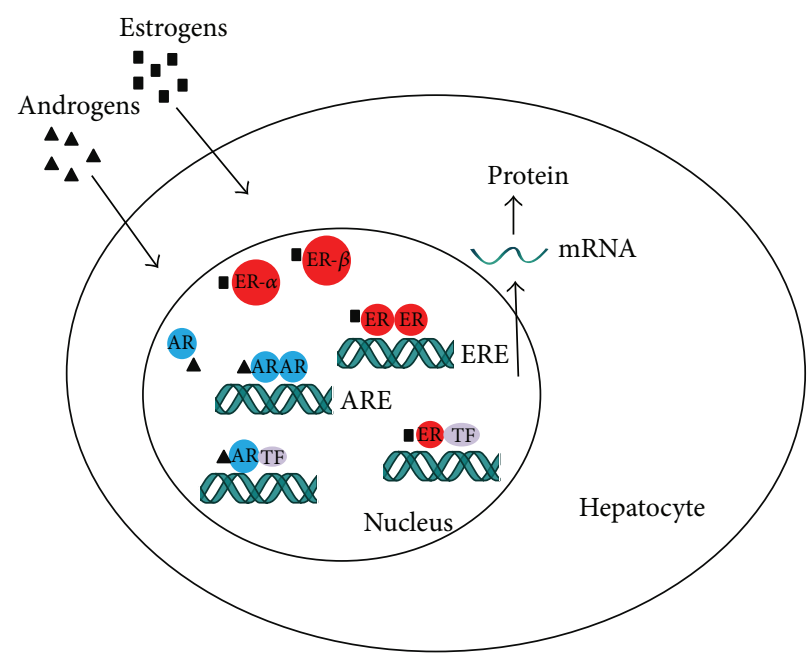

(a)

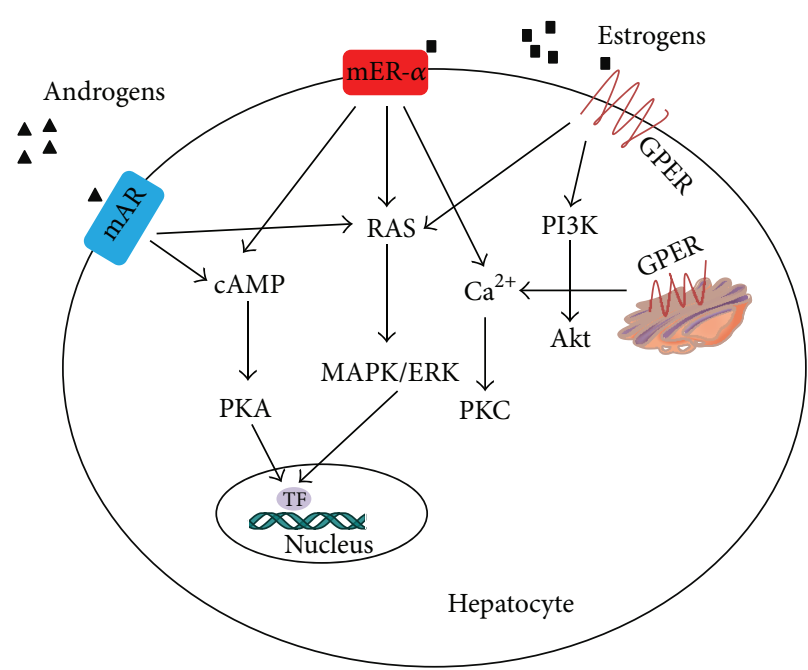

(b)

FIGURE 1: Action of estrogens and androgens via estrogen receptors (ERs) and androgen receptors (ARs) in the liver cells. (a) Genomic effects of estrogens and androgens via nuclear ERs and ARs. (b) Nongenomic effects of estrogens and androgens via membrane-associated ERs and ARs.

\subsection{Estrogens Regulate Lipid Homeostasis in the Liver.} Females, as compared with males, tend to store more energy in subcutaneous fat instead of in visceral fat. The liver is a key visceral organ for controlling energy storage, as the liver has high capacity for lipid transport, de novo lipogenesis, lipid oxidation, and lipolysis. Liver steatosis, as seen in the nonalcoholic fatty liver disease (NAFLD), is due to the excess of triglyceride (TG) accumulation within the hepatocytes. Incidence of hepatic steatosis is frequently associated with low levels of high density lipoprotein cholesterol (HDL-C) and high levels of low density lipoprotein cholesterol (LDLC) in the circulation. Epidemiological studies have showed higher plasma level of LDL-C and lower plasma level of HDL$\mathrm{C}$ in men and postmenopausal women compared with premenopausal women, suggesting that lower circulating estrogen levels may promote fat deposition in the liver [32]. Further evidence is supported by using OVX mouse model combined with pair-feeding between sham operation and OVX groups. Removal of the ovaries and thus the majority of endogenous estrogens in female mice results in increased fat proportion in the liver even when they are pair-fed with the same amount of calories as females with intact ovaries, which indicates the direct role of estrogens in inhibiting lipogenesis in the liver, rather than the secondary effects to OVX induced overfeeding [33]. In another E2-deficient aromatase knockout (ArKO) mouse model, spontaneous obesity and hepatic steatosis result from impaired fatty acid $\beta$-oxidation and elevated fatty acid synthase (FAS) in the liver in both female and male mice [34]. These findings are further supported by previous studies demonstrating that E2 inhibits lipogenic gene expression and lipid uptake in the liver by decreasing lipoprotein lipase activity, as well as promoting lipolysis by increasing expression of hormone-sensitive lipase and adipose TG lipase in the liver $[35,36]$.

ER- $\alpha$ is the predominant ER subtype presented in both male and female hepatocytes $[19,20]$. Estrogen signaling is important in both males and females in the regulation of lipogenesis, demonstrated by using animal models and human studies. Specifically, estrogens regulate the activity and expression of lipogenic genes to directly inhibit lipogenesis in several animal species [37, 38]. Liver enzymes may also be regulated by circulating estrogen levels. One study of genome-wide analyses demonstrated that the subtle oscillations of estrogens occurring during the estrous cycle are sufficient to influence liver gene expression, and that ERs are involved in the pulsatile synthesis of fatty acids and cholesterol in the liver [27]. Thus this study demonstrated the importance of the maintenance of estrogen oscillation to limit fat deposition in the hepatic tissues in females [27]. Additionally, treatment of the specific ER- $\alpha$ agonist PPT decreases weight, fat mass, and TG in the liver in both wild-type mice and obese $o b / o b$ mice $[39,40]$. Thus, the metabolically protective effect of estrogen may be attributed to estrogen signaling via ER- $\alpha$ [41].

This is further demonstrated by investigation of estrogen and estrogen signaling using knockout or transgenic animal models. Male and female ER- $\alpha$ knockout mice exhibit hepatic steatosis by increasing gene expression of lipogenic transcription factors such as sterol regulatory element binding protein 1c (SREBP-1c) and decreasing lipid transport genes [42, 43]. Mice with liver-specific ER- $\alpha$ knockout $[44,45]$ or liverspecific GPER knockout [46] show increases in fat accumulation in the liver and develop disturbed insulin signaling under high-fat diet (HFD) feeding. Thus, hepatic steatosis has been observed in both of the above genetic models, one with liverspecific ER- $\alpha$ knockout with functional GPER and the other with liver-specific GPER knockout with functional ER- $\alpha$. Thus, although it is widely recognized that estrogens regulate liver lipid metabolism and reduce triglyceride accumulation in the liver mainly via ER- $\alpha[47,48]$, both ER- $\alpha$ and GPER are required to be present in the liver to maintain lipid homeostasis. Estrogen is produced in males by aromatization 
of testosterone. Male but not female mice in which the aromatase gene has been deleted (ArKO) develop hepatic steatosis that can be normalized by estrogen treatment [49]. Thus, E2 treatment reduces fatty acid synthesis and lipid accumulation and prevented NAFLD in castrated male rats [50].

Hepatic TG and diacylglyceride increase in the livers of ER- $\alpha$ knockout male mice under HFD feeding, explained by dysregulation of insulin-stimulated ACC phosphorylation and DGAT1/2 protein levels [44]. Interestingly, a recent study using specific plasma membrane ER- $\alpha$ knockout has demonstrated that it is the membrane-localized ER- $\alpha$, but not nuclear ER- $\alpha$, that is responsible for protection from hyperlipidemia by decreasing expressions of many hepatic genes involved in lipid synthesis, at least in female mice with OVX [51]. Although ER- $\alpha$ is antilipogenic in the liver, the role of ER- $\beta$ in the liver is not consistent in the literature. ER- $\beta$ deficient mice have higher body weight but lower liver weight due to increased insulin sensitivity and decreased TG accumulation in the liver [52], indicating that ER- $\beta$ might be lipogenic and diabetogenic in the liver. Opposite finding has been reported where, different from treatment of E2 or ER- $\alpha$ agonists that decrease hepatic PPAR $\gamma$ expression, treatment of ER- $\beta$ agonist $8 \beta$-VE2 comparably elevates PPAR $\gamma$ expression to the same mRNA level as non-drug treated group in the liver of HFD-fed female rats with OVX [53]. Interestingly, all treatments of E2, ER- $\alpha$ agonist, or ER- $\beta$ agonist are capable of reducing TG accumulation in the liver of HFD-fed rats with OVX [53]. Thus, the mechanism for reduced hepatic lipid accumulation in both suppressed ER- $\beta$ signaling as seen in ER- $\beta$ knockout mice [52] and activated ER- $\beta$ signaling as seen in ER- $\beta$ agonist-treated rats [53] is awaiting further elucidation. Hepatic steatosis is also found in GPER deficient female mice fed with HFD rather than male mice [46]. Although both 6-month-old female and male GPER KO mice display increased body weight, only female mice had glucose intolerance, while male mice developed glucose intolerance at the age of 18 months [54]. Furthermore, GPER agonist G-1 decreases fatty acid synthesis and TG accumulation in both human and rodent pancreatic $\beta$ cells [55], but the effect of G-1 treatment on lipid metabolism in the liver is not clear. Both liver GPER and membrane-associated ER- $\alpha$ are critical for liver lipid metabolism. However, it is possible that GPER has greater impacts on male lipid regulation [54], whereas membrane-associated ER- $\alpha$ variant [51] may have greater impacts on female lipid regulation, as female livers have markedly higher expression of all three membrane-associated ER- $\alpha$ variants compared with male livers [56].

\subsection{Estrogens Regulate Glucose Homeostasis in the Liver.} Hepatic glucose homeostasis is determined by glucose uptake and glucose production. The major glucose transporter (GLUT) in the liver is GLUT2 that bidirectionally transports glucose across liver cell plasma membrane, efflux of glucose formed from gluconeogenesis or glycogenolysis out of liver cells, and uptake of circulating glucose into liver cells. Hepatic GLUT2 is upregulated by glucose, FAS, and insulin [57]. Since estrogen treatment has been shown to increase insulin synthesis and release [58], estrogens might indirectly increase GLUT2 expression in the liver, which has not been demonstrated yet. A recent study demonstrates that it is estriol, instead of E2, that downregulates GLUT2 in pregnant women during late stages of pregnancy whose peak postprandial glucose levels are much lower than glucose levels of healthy nonpregnant women [59]. Estrogens are also important in hepatic insulin clearance. Several lines of evidence show that intravenous conjugated estrogen treatment or low dose of oral contraceptive does not significantly alter insulin sensitivity but slightly increases hepatic insulin clearance in postmenopausal women $[60,61]$. Estrogens reduce gluconeogenesis and increase glycogen synthesis and storage in the liver, lowering circulating glucose level $[43,62]$. Additional observations using rodents with OVX that lacks majority of endogenous estrogens support the notion that estrogens lower glucose levels $[63,64]$. A recent study reports increased glucagon signaling due to increased amount of glucagon receptor that accounts for enhanced glucose production, accompanied with increased gluconeogenic enzymes in rats with OVX [65]. Interestingly, such changes cannot be prevented by $\mathrm{E} 2$ replacement, which indicates that disrupted liver glucose homeostasis following OVX is not merely caused by deficiency of endogenous E2 [65] but could be caused by deficiency of other ovarian hormones such as progesterone. Although classic nuclear progesterone receptor has not been found in the liver $[22,66]$, progestins can either bind to membrane-bound progesterone receptors [67] or bind to ARs [22] in human liver and carry metabolic effects. On the other hand, estrogens are also found to facilitate epinephrine's action via $\beta 2$-adrenergic receptor in regulating glycogenolysis and gluconeogenesis in the rat liver to increase circulating glucose level [68].

Estrogen signaling is important in both males and females in the regulation of glucose homeostasis, improving glucose tolerance and insulin sensitivity, demonstrated by using animal models and human studies [69-71]. Additionally, although estrogens do not affect hepatic glucose metabolism in vivo, estrogens increase insulin receptor to enhance glucose metabolism in vitro [72, 73].

ER- $\alpha$ deficient mice exhibit significantly impaired glucose tolerance and hepatic insulin resistance, while ER- $\beta$ deficient mice exhibit normal glucose tolerance, suggesting that ER$\alpha$ instead of ER- $\beta$ plays an important role in the regulation of hepatic glucose homeostasis [43]. The importance of ER$\alpha$ in the regulation of hepatic glucose tolerance is further supported by inadequate suppression of hepatic glucose production during hyperinsulinemic clamp study in ER- $\alpha$ deficient mice [74]. Although impaired glucose tolerance is seen in GPER1 knockout mice, GLUT2 and glucokinase are not affected [1], and glucose production in liver has not been measured yet. Hepatic PPAR $\gamma$ expression rises markedly following OVX in HFD-fed rats [53]. The rats treated with E2 or ER- $\alpha$ agonist have reduced PPAR $\gamma$ expression in the liver, whereas the rats treated with ER- $\beta$ agonist maintain a similarly high mRNA level of PPAR $\gamma$ as non-drug treated HFDfed rats with OVX. The sustained hepatic PPAR $\gamma$ gene expression correlates with increased glucose uptake into the liver of rats with OVX [53]. 
2.4. Estrogens Regulate Cholesterol Homeostasis in the Liver. Dyslipidemia is determined by decreased HDL but increased LDL and TG in the blood. The liver is the principal organ for cholesterol de novo biosynthesis, which is catalyzed by the rate limiting enzyme 3-hydroxy-3-methyl-glutaryl-CoA reductase (HMGR). The SREBP-1c is the master regulator of cholesterol by stimulating transcription of LDL and HMGR [75]. Postmenopausal women have elevated LDL and VLDL and lower HDL [76].

A previous in vitro study points out that HMGR promoter is induced by estrogen treatment in the breast cancer cell line MCF-7 but not in any hepatic cell line [77], indicating differential regulation of HMGR by estrogens among different tissues. Estrogen treatment does not increase cholesterol synthesis in liver cells in vitro. In an in vivo study using castrated male rats, DHT, but not E2, treatment increases phosphorylation of HMGR to decrease cholesterol synthesis in the liver [50]. Thus, at least in castrated male rats, androgen action is associated with downregulation of cholesterol biosynthesis in the liver.

Estrogens also decrease LDL level and increase HDL to promote cholesterol secretion into bile in postmenopausal women [78]. Total cholesterol and LDL are elevated in ArKO mice with E2 deficiency [79]. Increased hepatic HMGR activity and subsequently increased levels of cholesterol and LDL are seen in rats with OVX with reduced level of endogenous estrogens [65]. Estrogen replacement in both ArKO mice and rats with OVX normalizes the levels of LDL and cholesterol. The above mentioned cell, animal, and human studies collectively indicate important roles of estrogens in reducing LDL and increasing HDL.

ER- $\alpha$ is able to protect the liver from hypercholesterolemia $[47,48]$. To support this, lack of ER- $\alpha$ (whole body) is associated with increased expression of genes involved in lipid biosynthesis and lipid metabolism [43]. A male patient without functional ER- $\alpha$ has been reported with dyslipidemia [80], supporting the importance of ER- $\alpha$ in regulating cholesterol homeostasis. Consistently, the expressions of ER- $\alpha$ (and AR) and phosphorylated HMGR are significantly reduced in the human liver samples from male severe steatotic NAFLD patients compared with the liver samples from subnormal men [50].

Aromatase deficient mice without endogenous estrogen production exhibit obesity [79] and dyslipidemia [81] and mice with liver-specific ER- $\alpha$ knockout accumulate liver triglycerides and diacylglycerides [42, 43]. In contrast, ER$\alpha$ agonist PPT increases the expression of genes involved in lipid oxidation and metabolism [82]. Additionally, ER- $\alpha$ deficient mice and ER- $\alpha$ and ER- $\beta$ double knockout mice display increased body fat and serum cholesterol level, but these changes are not found in ER- $\beta$ deficient mice [83].

In GPER KO mice, LDL levels increase approximately by $200 \%$, but HDL levels do not show any significant differences from WT, which indicates that GPER mainly regulates the LDL metabolism instead of HDL [54]. A recent study shows that human individuals with hypofunctional P16L genetic variant of GPER have increased plasma LDL [84, 85]. In contrast, GPER activation upregulates LDL receptor expression in the liver via downregulation of proprotein convertase subtilisin kexin type 9 to enhance LDL metabolism [85]. Interestingly, animals with estrogen deficiency do not increase cholesterol synthesis; instead they decrease cholesterol catabolism by reducing activity of $7 \alpha$-hydroxylase, the enzyme that catalyzes the initial step in cholesterol catabolism and bile acid synthesis in calcium supplementation-induced hypercholesterolemia [86]. This study further demonstrates that estrogen treatment protects against increase in circulating level of cholesterol by activating of GPER [86].

\section{The Role of Androgens in Regulating Liver Energy Homeostasis}

3.1. Androgen Signaling. The major circulating androgens include dehydroepiandrosterone, androstenedione, testosterone, and dihydrotestosterone (DHT), in descending order of circulating concentrations. Only testosterone and DHT bind to the AR whereas the rest are considered as proandrogens. Within target cells, testosterone can be converted to active androgen DHT via $5 \alpha$-reductase or converted to E2 by aromatase.

ARs are expressed in the liver of male and female humans and rodents, and AR expression in the liver is sex dependent. In adult rats, basal AR expression in the liver of male rats is about 20 times higher than that in the liver of female rats [87]. AR expression is also age dependent in the liver of either sex, which is very low, almost undetectable, before puberty, increases in postpubertal life, and gradually declines during aging, reaching an almost nondetectable level after about 2224 months of age in rats [88]. The sex- and age-dependent AR expression in the liver is programed by a regulatory element in the AR gene promoter [89].

There are isoforms of ARs which are AR-A with $\mathrm{N}$ terminal truncated that resulted from proteolysis and AR-B with full length $[90,91]$; among these two AR isoforms, the AR-B with full length is more potent than AR-A [92]. It is not clear, however, which isoform of AR is dominant in the liver. Androgens, like estrogens, work on both nuclear and nonnuclear receptors. The genomic effect of androgens is achieved through activation of nuclear receptor, followed by binding to specific DNA known as androgen response element (ARE) motifs in its target gene [93]. AR can recruit other transcription factors such as AP-1, nuclear factor- $\kappa \mathrm{B}$, sex-determining region $\mathrm{Y}$, and the E26 transformation-specific family of transcription factors and bind to DNA regions other than ARE, to participate in transcription activation of many other genes [94]. The nonnuclear receptor of androgens function is independent of DNA interaction and is more rapid by interacting with cytoplasmic signal transduction pathways, including PKA and MAPK/ERK [95] (Figure 1). The AR knockout animals are well developed, but the membrane-only AR knockout animals are not established yet, and that is why the exact role of membrane AR in liver metabolism is unclear.

3.2. Androgens Regulate Lipid Homeostasis in the Liver. Many studies have shown that androgens and androgen signaling suppress the development of hepatic steatosis [96, 97]. One population-based cross-sectional study has reported a close 
association between low serum testosterone level and hepatic steatosis in men [98]. Mice with $5 \alpha$-reductase knockout do not covert testosterone to DHT. These mice upregulate expression for the genes involved in lipid storage and downregulate genes for fatty acid oxidation and accumulate lipid in their livers when they are fed with HFD [99]. An inhibitor of $5 \alpha$-reductase induces liver steatosis in male obese Zucker rats [100]. Therefore, normal level of active androgen is critical to prevent liver steatosis.

Besides androgen level, ARs are also critical in maintaining lipid metabolism in the liver. Testicular feminized (Tfm) mice with nonfunctional AR and very low serum testosterone levels greatly increase HFD feeding-induced hepatic lipid deposition compared with control male mice with functional $\mathrm{AR}$ and normal circulating levels of testosterone. Replacement of testosterone reduces lipid deposition in the liver of Tfm mice to a similar level to control males [101]. Moreover, Kelly et al. [101] found that the expressions of key regulatory enzymes for fatty acid synthesis, including acetyl-CoA carboxylase (ACC) and FAS, are elevated in placebo-treated Tfm mice comparing with placebo-treated wild-type littermates and Tfm mice receiving testosterone treatment, indicating that the action of androgens on lipid deposition is independent of AR and at least partially via affecting key regulatory lipogenic enzymes to protect against hepatic steatosis [101]. Male but not female hepatic ArKO mice fed with a normal chow diet developed liver steatosis at 10 months with reduced fatty acid oxidation and increased de novo fatty acid synthesis [102]. Thus, males with either functional AR or normal circulating testosterone level would maintain normal level of fatty acid synthesis and avoid increased lipid deposition in the liver.

Although many studies have shown that androgens protect against NAFLD $[50,103]$, other studies have reported an opposite finding that androgens promote NAFLD development and progression $[104,105]$. The inconsistencies might be due to different animal models employed and different treatments utilized in various studies. The findings reported by Münzker et al. indicate that the testosterone/DHT ratio is more important for NAFLD development and progression than concentrations of testosterone and/or DHT [106]. In contrast, the role of AR in hepatic steatosis is less controversial. The total AR knockout mice develop liver steatosis and insulin resistance in both male and female mice [107]. Hepatic AR knockout mice with HFD feeding also show hepatic steatosis and insulin resistance, via upregulation of hepatic expression of SREBP-1c, ACC, and PPAR $\gamma$ to increase lipid synthesis and downregulation of PPAR $\alpha$ to decrease fatty acid oxidation; interestingly, such effects are evident in males but absent in females $[102,108]$. Thus, hepatic AR plays more critical roles in maintaining liver lipid metabolism in males than in females.

Testosterone is either converted to E2 binding to ERs or converted to DHT binding to ARs. From the above studies, ARs are vital in regulating liver lipid homeostasis in both males and females [107], although hepatic ARs have greater impact in males than in females [102, 108]. In order to test the role of androgen-AR signaling in female metabolic process, Kanaya et al. replace DHT in female mice with OVX and find that those mice accumulate greater amount of fat in the liver and develop other symptoms and signs of metabolic dysfunction when these mice are fed with either a standard chow diet or HFD [109]. Therefore, androgen action has great impact on lipid metabolism in female livers.

Women have lower basal levels of androgens compared with males, and increased androgen level can affect metabolism in women. The role of androgens in females is not well established, but many lines of evidence indicate that hyperandrogenism in women with polycystic ovary syndrome (PCOS) increases risk of developing NAFLD. NAFLD is frequently present in PCOS women with excessive production of androgens by the ovaries and thus elevated circulating level of androgens, suggesting that abnormally high level of androgens in women may contribute to increased fat storage in the liver. It is noteworthy that the risk for NAFLD in women with PCOS is independent of obesity or insulin resistance but is triggered directly by the hepatotoxic, destructive effect in the liver, indicated by elevated level of alanine aminotransferase [110]. To summarize, normal level and signaling of androgens prevent hepatic lipid accumulation in males, while androgen deficiency in males is associated with fatty liver. Abnormally high level of androgens increases lipid deposition in the liver in females. Androgens therefore have differential effects in men and women.

3.3. Androgens Regulate Glucose Homeostasis in the Liver. Testosterone levels are lower in diabetic men than nondiabetic men [111]. Androgen deprivation therapy for prostate cancer patients lowers their circulating testosterone level and increases their risk of diabetes $[112,113]$ and not only increases circulating level of glucose but also diminishes pancreatic cell function [114]. Testosterone treatment markedly reduces circulating levels of glucose and TG in men [115].

GLUT2 directionally transports glucose across liver cell plasma membrane to maintain glucose homeostasis, as mentioned above in Section 2.3. Upregulation of GLUT2 plays a more critical role in regulating glucose export out of, rather than regulating glucose import into, the liver. It has been reported that blood glucose level, along with the mRNA and protein levels of GLUT2 in the liver, significantly increases following castration in male rats with deficiency of endogenous androgens [116]. Supplementation of testosterone or a combination of testosterone with E2 normalizes GLUT2 mRNA and protein levels in the livers of castrated rats, whereas treatment of E2 alone does not have any effect [116]. These findings suggest that testosterone maintains glucose homeostasis by regulating hepatic glucose output, and testosterone deprivation due to castration increases hepatic glucose output, induces hyperglycemia, and develops symptoms seen in type 2 diabetes and metabolic syndrome. Testosterone replacement restores GLUT2 mRNA and protein levels suggesting that testosterone may have a direct effect on GLUT2 transcription and translation of mRNA. Although the presence of ARE has not been identified in the promoter region of GLUT2, AR could function as a ligand-activated transcription factor by itself [117] or bind to some other coactivators $[118,119]$ to increase GLUT2 expression. 
In contrast, estrogens have little effect on hepatic GLUT4 and insulin receptor in male rats, but estrogens increase level of insulin receptor in HepG2, a liver cancer cell line [72]. Interestingly, insulin receptor mRNA level as well as insulin sensitivity is increased in a human liver cell line when being treated with testosterone [73]. Similarly, replacement of testosterone in castrated male mice also increases insulin receptor mRNA and protein levels in the liver and normalizes castration-induced glucose metabolic impairment [120]. Treatment of testosterone induces glycogen synthesis in both intact and castrated male rats $[108,121]$.

High testosterone level is associated with a low risk of diabetes in men, whereas it is associated with a high risk of diabetes in women [111, 122-124]. Excess androgen in women with PCOS impairs hepatic glucose metabolism by decreasing insulin-stimulated glucose uptake and glycogen synthesis and predisposes women with PCOS to insulin resistance $[125,126]$. Metformin, the most commonly used first-line drug to treat diabetes, is found to be effective to treat NAFLD and also suppresses the serum androgen concentration in PCOS patients $[127,128]$. Increased androgen activity in postmenopausal women correlates with impaired glucose tolerance $[129,130]$.

To summarize, testosterone in males favors hepatic glucose metabolism, whereas testosterone in females impairs it. Thus, androgens in males and females differentially regulate glucose homeostasis.

3.4. Androgens Regulate Cholesterol Homeostasis in the Liver. Old men have increased risks of developing dyslipidemia with increased serum cholesterol and LDL levels, and decreased HDL level, and testosterone replacement reverses such dyslipidemia [108]. Hepatic scavenger receptor class B member 1 (SR-1B) is important in regulating cholesterol uptake from circulating HDL. DHT treatment in castrated obese mice increases SR-1B compared with vehicle-treated castrated mice. At the same time, LDL secretion is decreased by DHT treatment. Cholesterol $7 \alpha$-hydroxylase, a key enzyme in bile formation and cholesterol removal, is also decreased after DHT treatment. All these above results provide a comprehensive explanation for how chronic androgen replacement can decrease serum levels of cholesterol and LDL via enhancing liver cholesterol uptake and via suppressing cholesterol removal, which in turn increases liver cholesterol accumulation [120]. A clinical study, however, shows that a single dose of testosterone treatment increases the serum cholesterol level after two days by increasing the expression of HMGR, the rate limiting enzyme for cholesterol de novo biosynthesis in the liver, but 15 days after the testosterone administration the cholesterol levels in the volunteers were back to baseline levels [131]. The mechanisms for the androgen induced upregulation of HMGCR transcription as well as the physiological consequences have not been investigated and need to be further elucidated.

\section{Summary and Future Directions}

The metabolic syndrome and its related diseases, such as obesity and diabetes, increase the health problems worldwide.

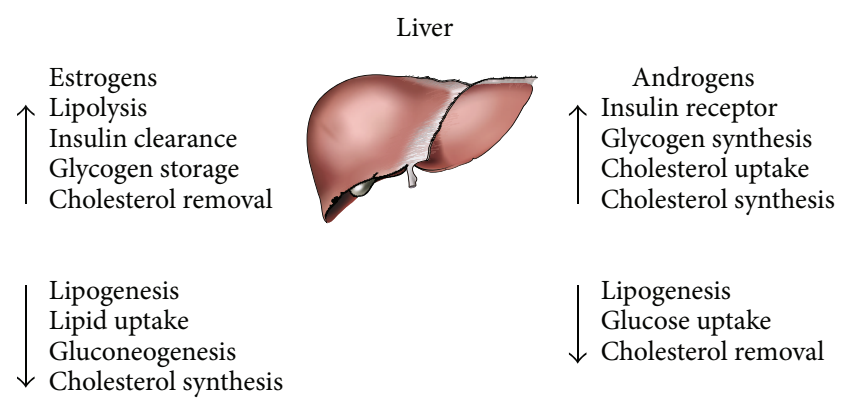

Figure 2: Metabolic effects of estrogens and androgens on regulation of lipid, glucose, and cholesterol in the liver.

The liver is the largest organ in the body that regulates lipid, glucose, and cholesterol homeostasis. Hepatic steatosis is one of the major manifestations of metabolic syndrome. Several lines of epidemiological data have suggested that sex hormones are associated in fatty different types of receptors. Estrogens seem to play protective roles against hepatic fat accumulation via suppressing lipogenesis and gluconeogenesis and promoting lipolysis and glycogen storage. Interestingly, estrogens increase both cholesterol synthesis and secretion. ER- $\alpha$ and its membrane form are more important in regulating energy homeostasis than ER- $\beta$. GPER and its roles in energy homeostasis are currently under intensive investigation; however, there is less evidence about the role of GPER in the liver compared with classic nuclear estrogen receptors. Since the GPER specific agonist and antagonist have been developed, further studies should apply these new chemicals to examine the role of GPER in liver energy homeostasis, yet the underlying molecular mechanisms are still unclear and longing for further investigation.

We review and discuss the roles played by estrogens, androgens, and their receptors in regulating liver energy homeostasis (Figure 2). The action mechanisms of estrogens are complicated in the body, as they work through multiple different subtypes of estrogen receptors. Estrogens promote liver glucose storage via increasing glucose transporters and glycogen synthesis and suppress liver glucose production via decreasing gluconeogenesis. Estrogens also actively participate in maintaining lipid and cholesterol balance and play protective roles against hepatic lipid accumulation, via suppressing lipogenesis, lipid uptake, and cholesterol synthesis and promoting lipolysis and cholesterol removal. Interestingly, estrogens increase both cholesterol synthesis and secretion. Classic nuclear ER- $\alpha$ and its membrane form are more important in regulating energy homeostasis than ER- $\beta$. GPER and its roles in energy homeostasis are currently under intensive investigation; however, there is less evidence about the roles of GPER in the liver compared with classic nuclear ERs. Since the GPER specific agonist and antagonist have been developed, further studies should apply these new chemical compounds to examine the role of GPER in liver energy homeostasis.

Androgens and nuclear AR have been shown to increase insulin receptor, decrease lipogenesis, and promote cholesterol storage in the liver. The membrane AR, however, is not 
well studied, which is also a potential research area to explore. It must be emphasized that the integration of nongenomic effects via membrane receptor signaling and genomic effects via nuclear receptor signaling of sex hormones is critical to produce the final sex hormone cellular outcomes.

Further investigation about differential androgen action in males and females is needed. Androgen deficiency, or excessive androgens as seen in women with PCOS, the most common endocrine disorder and cause of infertility among women of reproductive age, is closely associated with disturbed lipid and glucose metabolism in the liver.

\section{Abbreviations}

$\begin{array}{ll}\text { ARs: } & \text { Androgen receptors } \\ \text { ARE: } & \text { Androgen response element } \\ \text { ArKO: } & \text { Aromatase knockout } \\ \text { DHT: } & \text { Dihydrotestosterone } \\ \text { E2: } & \text { Estradiol } \\ \text { ER: } & \text { Estrogen receptor } \\ \text { ER- } \alpha: & \text { Estrogen receptor- } \alpha \\ \text { ER- } \beta \text { : } & \text { Estrogen receptor- } \beta \\ \text { ERE: } & \text { Estrogen response element } \\ \text { FAS: } & \text { Fatty acid synthase } \\ \text { GPER: } & \text { G protein-coupled receptor } \\ \text { GLUT: } & \text { Glucose transporter } \\ \text { HDL-C: } & \text { High density lipoprotein cholesterol } \\ \text { HFD: } & \text { High-fat diet } \\ \text { HMGR: } & \text { 3-Hydroxy-3-methyl-glutaryl-CoA reductase } \\ \text { LDL-C: } & \text { Low density lipoprotein cholesterol } \\ \text { NAFLD: } & \text { Nonalcoholic fatty liver disease } \\ \text { OVX: } & \text { Ovariectomy } \\ \text { PCOS: } & \text { Polycystic ovary syndrome } \\ \text { PPAR } \gamma: & \text { Proteasome proliferator activated receptor- } \gamma \\ \text { SR-1B: } & \text { Scavenger receptor class B member } 1 \\ \text { SREBP-1c: } & \text { Sterol regulatory element binding protein } 1 c \\ \text { TG: } & \text { Triglyceride. } \\ & \end{array}$

\section{Conflict of Interests}

The authors declare that there is no conflict of interests regarding the publication of this paper.

\section{Acknowledgments}

The authors thank funding from the Sigma Xi (G2012161930 and G20141015719335 to Minqian Shen), National Institutes of Health (R15 DK090823 to Haifei Shi), and Madalene and George Shetler Diabetes Research Award (to Haifei Shi). They also thank the Department of Biology at Miami University for providing Graduate Assistantship to Minqian Shen.

\section{References}

[1] U. E. A. Martensson, S. A. Salehi, S. Windahl et al., "Deletion of the $\mathrm{G}$ protein-coupled receptor 30 impairs glucose tolerance, reduces bone growth, increases blood pressure, and eliminates estradiol-stimulated insulin release in female mice," Endocrinology, vol. 150, no. 2, pp. 687-698, 2009.
[2] K. G. M. M. Alberti, P. Zimmet, and J. Shaw, "Metabolic syndrome-a new world-wide definition. A consensus statement from the International Diabetes Federation," Diabetic Medicine, vol. 23, no. 5, pp. 469-480, 2006.

[3] P. D. Home and G. Pacini, "Hepatic dysfunction and insulin insensitivity in type 2 diabetes mellitus: a critical target for insulin-sensitizing agents," Diabetes, Obesity and Metabolism, vol. 10, no. 9, pp. 699-718, 2008.

[4] R. J. Perry, V. T. Samuel, K. F. Petersen, and G. I. Shulman, "The role of hepatic lipids in hepatic insulin resistance and type 2 diabetes," Nature, vol. 510, no. 7503, pp. 84-91, 2014.

[5] M. C. Carr, "The emergence of the metabolic syndrome with menopause," Journal of Clinical Endocrinology and Metabolism, vol. 88, no. 6, pp. 2404-2411, 2003.

[6] M. Zitzmann, "Testosterone deficiency, insulin resistance and the metabolic syndrome," Nature Reviews Endocrinology, vol. 5, no. 12, pp. 673-681, 2009.

[7] M. Lazo and J. M. Clark, "The epidemiology of nonalcoholic fatty liver disease: a global perspective," Seminars in Liver Disease, vol. 28, no. 4, pp. 339-350, 2008.

[8] M. Lazo, R. Hernaez, M. S. Eberhardt et al., "Prevalence of nonalcoholic fatty liver disease in the United States: the third national health and nutrition examination survey, 1988-1994," American Journal of Epidemiology, vol. 178, no. 1, pp. 38-45, 2013.

[9] R. M. Williamson, J. F. Price, S. Glancy et al., "Prevalence of and risk factors for hepatic steatosis and nonalcoholic fatty liver disease in people with type 2 diabetes: the Edinburgh type 2 diabetes study," Diabetes Care, vol. 34, no. 5, pp. 1139-1144, 2011.

[10] J. D. Browning, L. S. Szczepaniak, R. Dobbins et al., "Prevalence of hepatic steatosis in an urban population in the United States: impact of ethnicity," Hepatology, vol. 40, no. 6, pp. 1387-1395, 2004.

[11] C. E. Kelley, A. J. Brown, A. M. Diehl, and T. L. Setji, "Review of nonalcoholic fatty liver disease in women with polycystic ovary syndrome," World Journal of Gastroenterology, vol. 20, no. 39, pp. 14172-14184, 2014.

[12] S. A. Polyzos, J. Kountouras, A. Tsatsoulis et al., "Sex steroids and sex hormone-binding globulin in postmenopausal women with nonalcoholic fatty liver disease," Hormones, vol. 12, no. 3, pp. 405-416, 2013.

[13] L. Carulli, A. Lonardo, S. Lombardini, G. Marchesini, and P. Loria, "Gender, fatty liver and GGT," Hepatology, vol. 44, no. 1, pp. 278-279, 2006.

[14] E. R. Simpson, "Sources of estrogen and their importance," Journal of Steroid Biochemistry and Molecular Biology, vol. 86, no. 3-5, pp. 225-230, 2003.

[15] H. Shi, S. P. D. S. Kumar, and X. Liu, "G protein-coupled estrogen receptor in energy homeostasis and obesity pathogenesis," Progress in Molecular Biology and Translational Science, vol. 114, pp. 193-250, 2013.

[16] M. Iavarone, P. Lampertico, C. Seletti et al., "The clinical and pathogenetic significance of estrogen receptor- $\beta$ expression in chronic liver diseases and liver carcinoma," Cancer, vol. 98, no. 3, pp. 529-534, 2003.

[17] V. Miceli, L. Cocciadiferro, M. Fregapane et al., "Expression of wild-type and variant estrogen receptor alpha in liver carcinogenesis and tumor progression," OMICS, vol. 15, no. 5, pp. 313-317, 2011.

[18] J. Cui, Y. Shen, and R. Li, "Estrogen synthesis and signaling pathways during aging: from periphery to brain," Trends in Molecular Medicine, vol. 19, no. 3, pp. 197-209, 2013. 
[19] D. Alvaro, G. Alpini, P. Onori et al., "Estrogens stimulate proliferation of intrahepatic biliary epithelium in rats," Gastroenterology, vol. 119, no. 6, pp. 1681-1691, 2000.

[20] G. G. Kuiper, K. Grandien, E. Enmark, J. Häggblad, S. Nilsson, and J.-Å. Gustafsson, "Comparison of the ligand binding specificity and transcript tissue distribution of estrogen receptors and alpha and beta," Endocrinology, vol. 138, no. 3, pp. 863-870, 1997.

[21] E. R. Lax, P. Tamulevicius, A. Müller, and H. Schriefers, "Hepatic nuclear estrogen receptor concentrations in the ratinfluence of age, sex, gestation, lactation and estrous cycle," Journal of Steroid Biochemistry, vol. 19, no. 2, pp. 1083-1088, 1983.

[22] A. J. Eisenfeld and R. F. Aten, "Estrogen receptors and androgen receptors in the mammalian liver," Journal of Steroid Biochemistry and Molecular Biology, vol. 27, no. 4-6, pp. 1109-1118, 1987.

[23] M. K. Mohamed and A. A. Abdel-Rahman, "Effect of long-term ovariectomy and estrogen replacement on the expression of estrogen receptor gene in female rats," European Journal of Endocrinology, vol. 142, no. 3, pp. 307-314, 2000.

[24] J. S. Finkelstein, H. Lee, S.-A. M. Burnett-Bowie et al., "Gonadal steroids and body composition, strength, and sexual function in men," The New England Journal of Medicine, vol. 369, no. 11, pp. 1011-1022, 2013.

[25] S. Handgraaf, E. Riant, A. Fabre et al., "Prevention of obesity and insulin resistance by estrogens requires $\mathrm{ER} \alpha$ activation function-2 (ER $\alpha \mathrm{AF}-2)$, whereas ER $\alpha \mathrm{AF}-1$ is dispensable," Diabetes, vol. 62, no. 12, pp. 4098-4108, 2013.

[26] P. Ciana, M. Raviscioni, P. Mussi et al., "In vivo imaging of transcriptionally active estrogen receptors," Nature Medicine, vol. 9, no. 1, pp. 82-86, 2003.

[27] A. Villa, S. Della Torre, A. Stell, J. Cook, M. Brown, and A. Maggi, "Tetradian oscillation of estrogen receptor $\alpha$ is necessary to prevent liver lipid deposition," Proceedings of the National Academy of Sciences of the United States of America, vol. 109, no. 29, pp. 11806-11811, 2012.

[28] K. L. Chambliss, Q. A. Wu, S. Oltmann et al., "Non-nuclear estrogen receptor alpha signaling promotes cardiovascular protection but not uterine or breast cancer growth in mice," The Journal of Clinical Investigation, vol. 120, no. 7, pp. 2319-2330, 2010.

[29] L. G. Kang, X. T. Zhang, Y. Xie et al., "Involvement of estrogen receptor variant ER-alpha36, not GPR30, in nongenomic estrogen signaling," Molecular Endocrinology, vol. 24, no. 4, pp. 709$721,2010$.

[30] M. C. Velarde, "Pleiotropic actions of estrogen: a mitochondrial matter," Physiological Genomics, vol. 45, no. 3, pp. 106-109, 2013.

[31] B. Nilsson, B. Olde, and L. M. F. Leeb-Lundberg, "G proteincoupled oestrogen receptor 1 (GPER1)/GPR30: a new player in cardiovascular and metabolic oestrogenic signalling," British Journal of Pharmacology, vol. 163, no. 6, pp. 1131-1139, 2011.

[32] L. Trapani, M. Segatto, and V. Pallottini, "Regulation and deregulation of cholesterol homeostasis: the liver as a metabolic 'power station"' World Journal of Hepatology, vol. 4, no. 6, pp. 184-190, 2012.

[33] T. M. D’Eon, S. C. Souza, M. Aronovitz, M. S. Obin, S. K. Fried, and A. S. Greenberg, "Estrogen regulation of adiposity and fuel partitioning. Evidence of genomic and non-genomic regulation of lipogenic and oxidative pathways," The Journal of Biological Chemistry, vol. 280, no. 43, pp. 35983-35991, 2005.

[34] C. R. Fisher, K. H. Graves, A. F. Parlow, and E. R. Simpson, "Characterization of mice deficient in aromatase (ArKO) because of targeted disruption of the cyp19 gene," Proceedings of the National Academy of Sciences of the United States of America, vol. 95, no. 12, pp. 6965-6970, 1998.

[35] M. Shen, S. P. Kumar, and H. Shi, "Estradiol regulates insulin signaling and inflammation in adipose tissue," Hormone Molecular Biology and Clinical Investigation, vol. 17, no. 2, pp. 99-107, 2014.

[36] A. Foryst-Ludwig and U. Kintscher, "Metabolic impact of estrogen signalling through ERalpha and ERbeta," Journal of Steroid Biochemistry and Molecular Biology, vol. 122, no. 1-3, pp. 74-81, 2010.

[37] S. Courtney, S. Talbot, and R. Manning, "Early effects of oestrogen treatment on lipogenesis de novo and on biosynthesis of triacylglycerol from fatty acids in male chick liver," International Journal of Biochemistry, vol. 20, no. 1, pp. 73-78, 1988.

[38] P. M. Gowri, S. Sengupta, S. Bertera, and B. S. Katzenellenbogen, "Lipinl regulation by estrogen in uterus and liver: implications for diabetes and fertility," Endocrinology, vol. 148, no. 8, pp. 3685-3693, 2007.

[39] H. Gao, S. Fält, A. Sandelin, J.-Å. Gustafsson, and K. DahlmanWright, "Genome-wide identification of estrogen receptor $\alpha$ binding sites in mouse liver," Molecular Endocrinology, vol. 22, no. 1, pp. 10-22, 2008.

[40] V. Ribas, M. T. A. Nguyen, D. C. Henstridge et al., "Impaired oxidative metabolism and inflammation are associated with insulin resistance in ERalpha-deficient mice," The American Journal of Physiology_Endocrinology and Metabolism, vol. 298, no. 2, pp. E304-E319, 2010.

[41] C. Linnér, J. Svartberg, A. Giwercman, and Y. L. Giwercman, "Estrogen receptor alpha single nucleotide polymorphism as predictor of diabetes type 2 risk in hypogonadal men," Aging Male, vol. 16, no. 2, pp. 52-57, 2013.

[42] P. A. Heine, J. A. Taylor, G. A. Iwamoto, D. B. Lubahn, and P. S. Cooke, "Increased adipose tissue in male and female estrogen receptor- $\alpha$ knockout mice," Proceedings of the National Academy of Sciences of the United States of America, vol. 97, no. 23, pp. 12729-12734, 2000.

[43] G. Bryzgalova, H. Gao, B. Ahren et al., "Evidence that oestrogen receptor-alpha plays an important role in the regulation of glucose homeostasis in mice: insulin sensitivity in the liver," Diabetologia, vol. 49, no. 3, pp. 588-597, 2006.

[44] L. Zhu, M. N. Martinez, C. H. Emfinger, B. T. Palmisano, and J. M. Stafford, "Estrogen signaling prevents diet-induced hepatic insulin resistance in male mice with obesity," The American Journal of Physiology - Endocrinology and Metabolism, vol. 306, no. 10, pp. E1188-E1197, 2014.

[45] L. Zhu, W. C. Brown, Q. Cai et al., "Estrogen treatment after ovariectomy protects against fatty liver and may improve pathway-selective insulin resistance," Diabetes, vol. 62, no. 2, pp. 424-434, 2013.

[46] L. Meoli, J. Isensee, V. Zazzu et al., "Sex- and age-dependent effects of Gpr30 genetic deletion on the metabolic and cardiovascular profiles of diet-induced obese mice," Gene, vol. 540, no. 2, pp. 210-216, 2014.

[47] M. H. Faulds, C. Zhao, K. Dahlman-Wright, and J.-Å. Gustafsson, "The diversity of sex steroid action: regulation of metabolism by estrogen signaling," Journal of Endocrinology, vol. 212, no. 1, pp. 3-12, 2012.

[48] C. Lemieux, D. Phaneuf, F. Labrie, V. Giguère, D. Richard, and Y. Deshaies, "Estrogen receptor alpha-mediated adipositylowering and hypocholesterolemic actions of the selective estrogen receptor modulator acolbifene," International Journal of Obesity, vol. 29, no. 10, pp. 1236-1244, 2005. 
[49] K. N. Hewitt, K. Pratis, M. E. E. Jones, and E. R. Simpson, "Estrogen replacement reverses the hepatic steatosis phenotype in the male aromatase knockout mouse," Endocrinology, vol. 145, no. 4, pp. 1842-1848, 2004.

[50] H. Zhang, Y. W. Liu, L. Wang et al., "Differential effects of estrogen/androgen on the prevention of nonalcoholic fatty liver disease in the male rat," Journal of Lipid Research, vol. 54, no. 2, pp. 345-357, 2013.

[51] A. Pedram, M. Razandi, F. O’Mahony, H. Harvey, B. J. Harvey, and E. R. Levin, "Estrogen reduces lipid content in the liver exclusively from membrane receptor signaling," Science Signaling, vol. 6, no. 276, p. ra36, 2013.

[52] A. Foryst-Ludwig, M. Clemenz, S. Hohmann et al., "Metabolic actions of estrogen receptor beta $(\mathrm{ER} \beta)$ are mediated by a negative cross-talk with PPAR $\gamma$," PLoS Genetics, vol. 4, no. 6, Article ID e1000108, 2008.

[53] C. Weigt, T. Hertrampf, F. M. Kluxen et al., "Molecular effects of ER alpha- and beta-selective agonists on regulation of energy homeostasis in obese female Wistar rats," Molecular and Cellular Endocrinology, vol. 377, no. 1-2, pp. 147-158, 2013.

[54] G. Sharma, C. Hu, J. L. Brigman, G. Zhu, H. J. Hathaway, and E. R. Prossnitz, "GPER deficiency in male mice results in insulin resistance, dyslipidemia, and a proinflammatory state," Endocrinology, vol. 154, no. 11, pp. 4136-4145, 2013.

[55] J. P. Tiano, V. Delghingaro-Augusto, C. Le May et al., "Estrogen receptor activation reduces lipid synthesis in pancreatic islets and prevents beta cell failure in rodent models of type 2 diabetes," The Journal of Clinical Investigation, vol. 121, no. 8, pp. 3331-3342, 2011.

[56] D. L. Irsik, P. K. Carmines, and P. H. Lane, "Classical Estrogen Receptors and ER $\alpha$ splice variants in the mouse," PLoS ONE, vol. 8, no. 8, Article ID e70926, 2013.

[57] J. C. Stanley, "The regulation of glucose production. The role of liver glycogen and gluconeogenesis in the liver and kidney cortex," British Journal of Anaesthesia, vol. 53, no. 2, pp. 137-146, 1981.

[58] M. Barton and E. R. Prossnitz, "Emerging roles of GPER in diabetes and atherosclerosis," Trends in Endocrinology \& Metabolism, vol. 26, no. 4, pp. 185-192, 2015.

[59] N. Yamabe, K. S. Kang, W. Lee, S. Kim, and B. T. Zhu, "Estriol blunts postprandial blood glucose rise in male rats through regulating intestinal glucose transporters," The American Journal of Physiology-Endocrinology And Metabolism, vol. 308, no. 5, pp. E370-E379, 2015.

[60] A. J. Scheen, B. J. Jandrain, D. M. P. Humblet, C. B. Jaminet, U. J. Gaspard, and P. J. Lefebvre, "Effects of a 1-year treatment with a low-dose combined oral contraceptive containing ethinyl estradiol and cyproterone acetate on glucose and insulin metabolism," Fertility and Sterility, vol. 59, no. 4, pp. 797-802, 1993.

[61] R. E. Van Pelt, W. S. Gozansky, R. S. Schwartz, and W. M. Kohrt, "Intravenous estrogens increase insulin clearance and action in postmenopausal women," The American Journal of PhysiologyEndocrinology and Metabolism, vol. 285, no. 2, pp. E311-E317, 2003.

[62] H. Ahmed-Sorour and C. J. Bailey, "Role of ovarian hormones in the long-term control of glucose homeostasis glycogen formation and gluconeogenesis," Annals of Nutrition and Metabolism, vol. 25, no. 4, pp. 208-212, 1981.

[63] V. Saengsirisuwan, S. Pongseeda, M. Prasannarong, K. Vichaiwong, and C. Toskulkao, "Modulation of insulin resistance in ovariectomized rats by endurance exercise training and estrogen replacement," Metabolism-Clinical and Experimental, vol. 58, no. 1, pp. 38-47, 2009.

[64] M. Feigh, K. V. Andreassen, S. T. Hjuler et al., "Oral salmon calcitonin protects against impaired fasting glycemia, glucose intolerance, and obesity induced by high-fat diet and ovariectomy in rats," Menopause, vol. 20, no. 7, pp. 785-794, 2013.

[65] M. Nigro, A. T. Santos, C. S. Barthem et al., "A change in liver metabolism but not in brown adipose tissue thermogenesis is an early event in ovariectomy-induced obesity in rats," Endocrinology, vol. 155, no. 8, pp. 2881-2891, 2014.

[66] S. M. Varas and G. A. Jahn, “The expression of estrogen, prolactin, and progesterone receptors in mammary gland and liver of female rats during pregnancy and early postpartum: regulation by thyroid hormones," Endocrine Research, vol. 31, no. 4, pp. 357-370, 2005.

[67] O. Selmin, P. A. Thorne, F. M. Blachere, P. D. Johnson, and D. F. Romagnolo, "Transcriptional activation of the membranebound progesterone receptor (mPR) by dioxin, in endocrineresponsive tissues," Molecular Reproduction and Development, vol. 70, no. 2, pp. 166-174, 2005.

[68] S. Shima, N. Okeyama, and N. Akamatu, "Effects of oestrogen on adenylate cyclase system and glucose output in rat liver," Biochemical Journal, vol. 257, no. 2, pp. 407-411, 1989.

[69] K. Takeda, K. Toda, T. Saibara et al., "Progressive development of insulin resistance phenotype in male mice with complete aromatase (CYP19) deficiency," Journal of Endocrinology, vol. 176, no. 2, pp. 237-246, 2003.

[70] E. R. Simpson, M. Misso, K. N. Hewitt et al., "Estrogen-the good, the bad, and the unexpected," Endocrine Reviews, vol. 26, no. 3, pp. 322-330, 2005.

[71] H. Gao, G. Bryzgalova, E. Hedman et al., "Long-term administration of estradiol decreases expression of hepatic lipogenic genes and improves insulin sensitivity in ob/ob mice: a possible mechanism is through direct regulation of signal transducer and activator of transcription 3," Molecular Endocrinology, vol. 20, no. 6, pp. 1287-1299, 2006.

[72] P. Xie, M.-L. Liu, Y.-P. Gu et al., "Oestrogen improves glucose metabolism and insulin signal transduction in HepG2 cells," Clinical and Experimental Pharmacology and Physiology, vol. 30, no. 9, pp. 643-648, 2003.

[73] C. Parthasarathy, V. N. Renuka, and K. Balasubramanian, "Sex steroids enhance insulin receptors and glucose oxidation in Chang liver cells," Clinica Chimica Acta, vol. 399, no. 1-2, pp. 49-53, 2009.

[74] L. Lundholm, G. Bryzgalova, H. Gao et al., "The estrogen receptor $\alpha$-selective agonist propyl pyrazole triol improves glucose tolerance in ob/ob mice; potential molecular mechanisms," Journal of Endocrinology, vol. 199, no. 2, pp. 275-286, 2008.

[75] P. J. Espenshade and A. L. Hughes, "Regulation of sterol synthesis in eukaryotes," Annual Review of Genetics, vol. 41, pp. 401427, 2007.

[76] M. A. Espeland, S. M. Marcovina, V. Miller et al., "Effect of postmenopausal hormone therapy on lipoprotein(a) concentration," Circulation, vol. 97, no. 10, pp. 979-986, 1998.

[77] L. Di Croce, G. P. Vicent, A. Pecci, G. Bruscalupi, A. Trentalance, and M. Beato, "The promoter of the rat 3-hydroxy-3methylglutaryl coenzyme a reductase gene contains a tissuespecific estrogen-responsive region," Molecular Endocrinology, vol. 13, no. 8, pp. 1225-1236, 1999.

[78] M. Darabi, M. Rabbani, M. Ani, E. Zarean, M. Panjehpour, and A. Movahedian, "Increased leukocyte ABCA1 gene expression 
in post-menopausal women on hormone replacement therapy," Gynecological Endocrinology, vol. 27, no. 9, pp. 701-705, 2011.

[79] M. E. E. Jones, A. W. Thorburn, K. L. Britt et al., "Aromatasedeficient (ArKO) mice have a phenotype of increased adiposity," Proceedings of the National Academy of Sciences of the United States of America, vol. 97, no. 23, pp. 12735-12740, 2000.

[80] R. P. A. Barros and J.-Å. Gustafsson, "Estrogen receptors and the metabolic network," Cell Metabolism, vol. 14, no. 3, pp. 289-299, 2011.

[81] Y. Nemoto, K. Toda, M. Ono et al., "Altered expression of fatty acid-metabolizing enzymes in aromatase-deficient mice," The Journal of Clinical Investigation, vol. 105, no. 12, pp. 1819-1825, 2000.

[82] M. Moreno, P. Ordoñez, A. Alonso, F. Díaz, J. Tolivia, and C. González, "Chronic $17 \beta$-estradiol treatment improves skeletal muscle insulin signaling pathway components in insulin resistance associated with aging," Age, vol. 32, no. 1, pp. 1-13, 2010.

[83] C. Ohlsson, N. Hellberg, P. Parini et al., "Obesity and disturbed lipoprotein profile in estrogen receptor- $\alpha$-deficient male mice," Biochemical and Biophysical Research Communications, vol. 278, no. 3, pp. 640-645, 2000.

[84] R. D. Feldman, R. Gros, Q. Ding et al., "A common hypofunctional genetic variant of GPER is associated with increased blood pressure in women," British Journal of Clinical Pharmacology, vol. 78, no. 6, pp. 1441-1452, 2014.

[85] Y. Hussain, Q. Ding, P. W. Connelly et al., "G-protein estrogen receptor as a regulator of low-density lipoprotein cholesterol metabolism: cellular and population genetic studies," Arteriosclerosis, Thrombosis, and Vascular Biology, vol. 35, no. 1, pp. 213-221, 2014.

[86] S. T. Li, Y. Li, H. Ning et al., "Calcium supplementation increases circulating cholesterol by reducing its catabolism via GPER and TRPC1-dependent pathway in estrogen deficient women," International Journal of Cardiology, vol. 168, no. 3, pp. 25482560, 2013.

[87] B. Chatterjee, C. S. Song, M. H. Jung et al., "Targeted overexpression of androgen receptor with a liver-specific promoter in transgenic mice," Proceedings of the National Academy of Sciences of the United States of America, vol. 93, no. 2, pp. 728733, 1996.

[88] P. C. Supakar and A. K. Roy, "Role of transcription factors in the age-dependent regulation of the androgen receptor gene in rat liver," Biological Signals, vol. 5, no. 3, pp. 170-179, 1996.

[89] A. K. Roy, R. L. Vellanoweth, S. Chen et al., "The evolutionary tangle of aging, sex, and reproduction and an experimental approach to its molecular dissection," Experimental Gerontology, vol. 31, no. 1-2, pp. 83-94, 1996.

[90] C. M. Wilson and M. J. McPhaul, "A and B forms of the androgen receptor are present in human genital skin fibroblasts," Proceedings of the National Academy of Sciences, vol. 91, no. 4, pp. 1234-1238, 1994.

[91] C. W. Gregory, B. He, and E. M. Wilson, “The putative androgen receptor-A form results from in vitro proteolysis," Journal of Molecular Endocrinology, vol. 27, no. 3, pp. 309-319, 2001.

[92] R. Butler, P. N. Leigh, M. J. McPhaul, and J.-M. Gallo, “Truncated forms of the androgen receptor are associated with polyglutamine expansion in X-linked spinal and bulbar muscular atrophy," Human Molecular Genetics, vol. 7, no. 1, pp. 121-127, 1998.

[93] M. Beato, “Gene regulation by steroid hormones," Cell, vol. 56, no. 3, pp. 335-344, 1989.
[94] S. Vlahopoulos, W. E. Zimmer, G. Jenster et al., "Recruitment of the androgen receptor via serum response factor facilitates expression of a myogenic gene," The Journal of Biological Chemistry, vol. 280, no. 9, pp. 7786-7792, 2005.

[95] C. D. Foradori, M. J. Weiser, and R. J. Handa, "Non-genomic actions of androgens," Frontiers in Neuroendocrinology, vol. 29, no. 2, pp. 169-181, 2008.

[96] A. Jacqueson, M. Thevenin, J. M. Warnet, J. R. Claude, and R. Truhaut, "Comparative study of the protective effect of an anabolic steroid. The 19-nortestosterone-phenylpropionate (19 NTPP), on liver steatosis induced by Amanita phalloides and white phosphorus in rats," Archives of Toxicology Supplement, no. 1, pp. 193-196, 1978.

[97] B. Saint-Aubert, P. Vic, C. Brissac et al., "Hepatic regeneration in the rat after subtotal (90\%) hepatectomy treated with testosterone," Comptes Rendus des Séances de l’Académie des Sciences Série D: Sciences naturelles, vol. 291, no. 7, pp. 653-655, 1980.

[98] H. Völzke, N. Aumann, A. Krebs et al., "Hepatic steatosis is associated with low serum testosterone and high serum DHEAS levels in men," International Journal of Andrology, vol. 33, no. 1, pp. 45-53, 2010.

[99] J. K. Dowman, L. J. Hopkins, G. M. Reynolds et al., "Loss of $5 \alpha$-Reductase Type 1 accelerates the development of hepatic steatosis but protects against hepatocellular carcinoma in male mice," Endocrinology, vol. 154, no. 12, pp. 4536-4547, 2013.

[100] D. E. W. Livingstone, P. Barat, E. M. Di Rollo et al., “ $5 \alpha$-Reductase type 1 deficiency or inhibition predisposes to insulin resistance, hepatic steatosis, and liver fibrosis in rodents," Diabetes, vol. 64, no. 2, pp. 447-458, 2015.

[101] D. M. Kelly, J. E. Nettleship, S. Akhtar et al., "Testosterone suppresses the expression of regulatory enzymes of fatty acid synthesis and protects against hepatic steatosis in cholesterol-fed androgen deficient mice," Life Sciences, vol. 109, no. 2, pp. 95103, 2014.

[102] H.-Y. Lin, I.-C. Yu, R.-S. Wang et al., "Increased hepatic steatosis and insulin resistance in mice lacking hepatic androgen receptor," Hepatology, vol. 47, no. 6, pp. 1924-1935, 2008.

[103] Z. Magyar, G. Bekesi, K. Racz et al., "Increased total scavenger capacity and decreased liver fat content in rats fed dehydroepiandrosterone and its sulphate on a high-fat diet," Gerontology, vol. 57, no. 4, pp. 343-349, 2011.

[104] H. Jones, V. S. Sprung, C. J. A. Pugh et al., "Polycystic ovary syndrome with hyperandrogenism is characterized by an increased risk of hepatic steatosis compared to nonhyperandrogenic PCOS phenotypes and healthy controls, independent of obesity and insulin resistance," Journal of Clinical Endocrinology and Metabolism, vol. 97, no. 10, pp. 3709-3716, 2012.

[105] P. A. Schwingel, C. C. Zoppi, and H. P. Cotrim, "Increased liver steatosis in anabolic-androgenic steroid users: more evidence towards toxicant-associated fatty liver disease development," Liver International, vol. 31, no. 8, pp. 1240-1241, 2011.

[106] J. Münzker, D. Hofer, C. Trummer et al., "Testosterone to dihydrotestosterone ratio as a new biomarker for an adverse metabolic phenotype in the polycystic ovary syndrome," The Journal of Clinical Endocrinology \& Metabolism, vol. 100, no. 2, pp. 653-660, 2015.

[107] H.-Y. Lin, Q. Xu, S. Yeh, R.-S. Wang, J. D. Sparks, and C. Chang, "Insulin and leptin resistance with hyperleptinemia in mice lacking androgen receptor," Diabetes, vol. 54, no. 6, pp. 17171725, 2005. 
[108] D. M. Kelly and T. H. Jones, "Testosterone: a metabolic hormone in health and disease," Journal of Endocrinology, vol. 217, no. 3, pp. R25-R45, 2013.

[109] N. Kanaya, S. Vonderfecht, and S. Chen, "Androgen (dihydrotestosterone)-mediated regulation of food intake and obesity in female mice," Journal of Steroid Biochemistry and Molecular Biology, vol. 138, pp. 100-106, 2013.

[110] A. Bohdanowicz-Pawlak, A. Lenarcik-Kabza, A. Brona et al., "Non-alcoholic fatty liver disease in women with polycystic ovary syndrome-clinical and metabolic aspects and lipoprotein lipase gene polymorphism," Endokrynologia Polska, vol. 65, no. 6, pp. 416-421, 2014.

[111] E. L. Ding, Y. Song, V. S. Malik, and S. Liu, "Sex differences of endogenous sex hormones and risk of type 2 diabetes: a systematic review and meta-analysis," The Journal of the American Medical Association, vol. 295, no. 11, pp. 1288-1299, 2006.

[112] N. L. Keating, A. J. O’Malley, S. J. Freedland, and M. R. Smith, "Diabetes and cardiovascular disease during androgen deprivation therapy: observational study of veterans with prostate cancer," Journal of the National Cancer Institute, vol. 104, no. 19, pp. 1518-1523, 2012.

[113] M. Grossmann and J. D. Zajac, "Androgen deprivation therapy in men with prostate cancer: how should the side effects be monitored and treated?" Clinical Endocrinology, vol. 74, no. 3, pp. 289-293, 2011.

[114] M. Inaba, Y. Otani, K. Nishimura et al., "Marked hyperglycemia after androgen-deprivation therapy for prostate cancer and usefulness of pioglitazone for its treatment," Metabolism: Clinical and Experimental, vol. 54, no. 1, pp. 55-59, 2005.

[115] G. Corona, M. Monami, G. Rastrelli et al., “Type 2 diabetes mellitus and testosterone: a meta-analysis study," International Journal of Andrology, vol. 34, no. 6, part 1, pp. 528-540, 2011.

[116] T. Muthusamy, P. Murugesan, and K. Balasubramanian, "Sex steroids deficiency impairs glucose transporter 4 expression and its translocation through defective Akt phosphorylation in target tissues of adult male rat," Metabolism: Clinical and Experimental, vol. 58, no. 11, pp. 1581-1592, 2009.

[117] I. J. Mcewan and J.-A. Gustafsson, "Interaction of the human androgen receptor transactivation function with the general transcription factor TFIIF," Proceedings of the National Academy of Sciences of the United States of America, vol. 94, no. 16, pp. 8485-8490, 1997.

[118] S. Yeh and C. Chang, "Cloning and characterization of a specific coactivator, ARA70, for the androgen receptor in human prostate cells," Proceedings of the National Academy of Sciences of the United States of America, vol. 93, no. 11, pp. 5517-5521, 1996.

[119] P. Aarnisalo, J. J. Palvimo, and O. A. Jänne, "CREB-binding protein in androgen receptor-mediated signaling," Proceedings of the National Academy of Sciences of the United States of America, vol. 95, no. 5, pp. 2122-2127, 1998.

[120] S. Movérare-Skrtic, K. Venken, N. Andersson et al., "Dihydrotestosterone treatment results in obesity and altered lipid metabolism in orchidectomized mice," Obesity, vol. 14, no. 4, pp. 662-672, 2006.

[121] E. Bergamini, "Different mechanisms in testosterone action on glycogen metabolism in rat perineal and skeletal muscles," Endocrinology, vol. 96, no. 1, pp. 77-84, 1975.

[122] E. C. Tok, D. Ertunc, C. Evruke, and S. Dilek, "The androgenic profile of women with non-insulin-dependent diabetes mellitus," Journal of Reproductive Medicine for the Obstetrician and Gynecologist, vol. 49, no. 9, pp. 746-752, 2004.
[123] J.-Y. Oh, E. Barrett-Connor, N. M. Wedick, and D. L. Wingard, "Endogenous sex hormones and the development of type 2 diabetes in older men and women: the Rancho Bernardo Study," Diabetes Care, vol. 25, no. 1, pp. 55-60, 2002.

[124] B. Andersson, P. Märin, L. Lissner, A. Vermeulen, and P. Björntorp, "Testosterone concentrations in women and men with NIDDM," Diabetes Care, vol. 17, no. 5, pp. 405-411, 1994.

[125] K. Højlund, "Metabolism and insulin signaling in common metabolic disorders and inherited insulin resistance," Danish Medical Journal, vol. 61, no. 7, Article ID B4890, 2014.

[126] L. Velez and A. Motta, "Association between polycystic ovary syndrome and metabolic syndrome," Current Medicinal Chemistry, vol. 21, no. 35, pp. 3999-4012, 2014.

[127] A. F. G. Cicero, E. Tartagni, and S. Ertek, "Metformin and its clinical use: new insights for an old drug in clinical practice," Archives of Medical Science, vol. 8, no. 5, pp. 907-917, 2012.

[128] M. O. Weickert, P. Hodges, B. K. Tan, and H. S. Randeva, "Neuroendocrine and endocrine dysfunction in the hyperinsulinemic PCOS patient: the role of metformin," Minerva Endocrinologica, vol. 37, no. 1, pp. 25-40, 2012.

[129] H. Larsson and B. Ahrén, "Androgen activity as a risk factor for impaired glucose tolerance in postmenopausal women," Diabetes Care, vol. 19, no. 12, pp. 1399-1403, 1996.

[130] M. Maggio, F. Lauretani, G. P. Ceda et al., "Association of hormonal dysregulation with metabolic syndrome in older women: data from the InCHIANTI study," The American Journal of Physiology-Endocrinology and Metabolism, vol. 292, no. 1, pp. E353-E358, 2007.

[131] N. Gårevik, C. Skogastierna, A. Rane, and L. Ekström, “Single dose testosterone increases total cholesterol levels and induces the expression of HMG CoA Reductase," Substance Abuse: Treatment, Prevention, and Policy, vol. 7, article 12, 2012. 


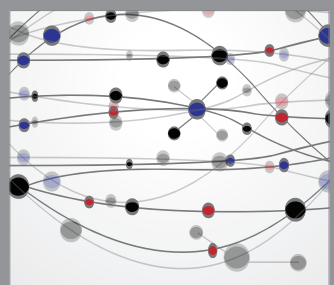

The Scientific World Journal
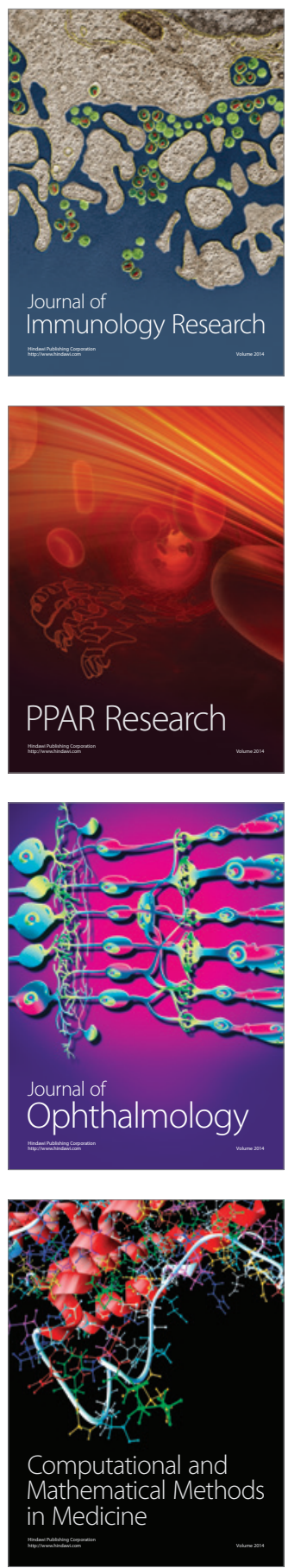

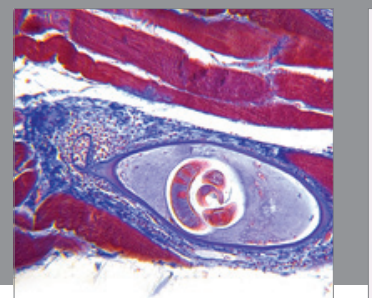

Gastroenterology

Research and Practice
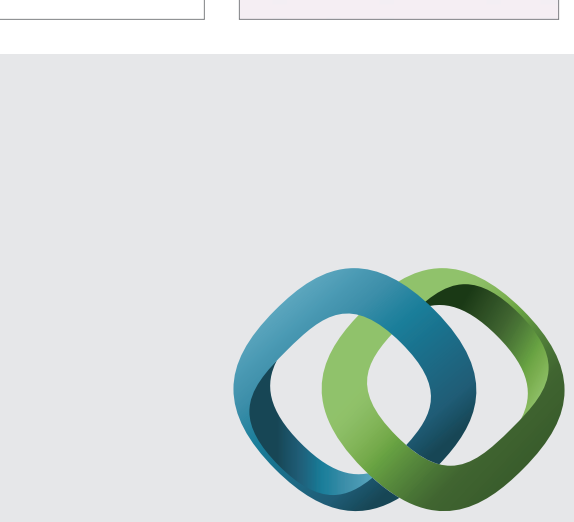

\section{Hindawi}

Submit your manuscripts at

http://www.hindawi.com
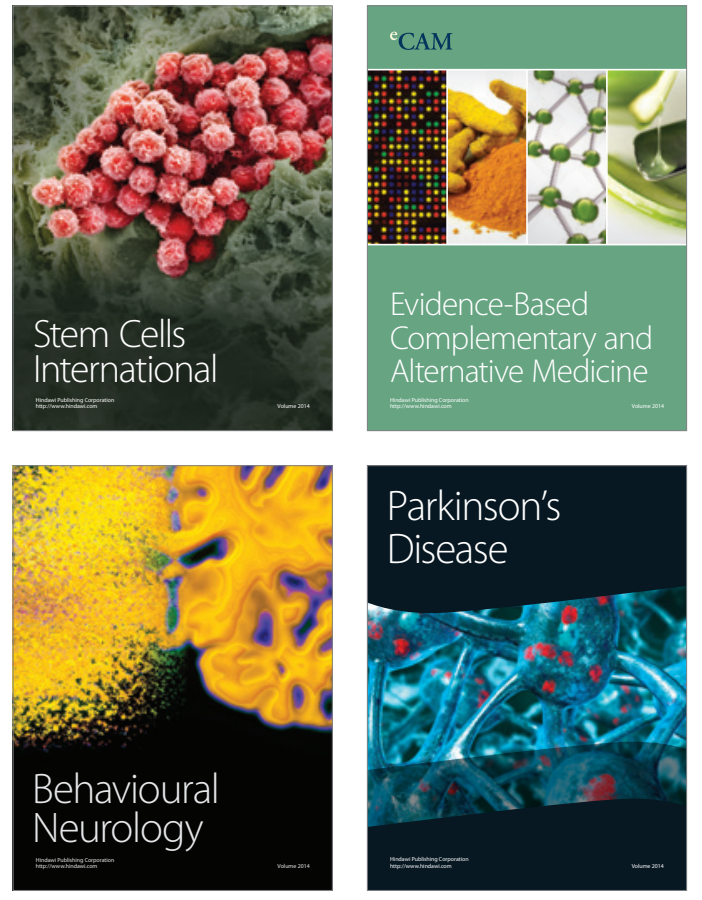
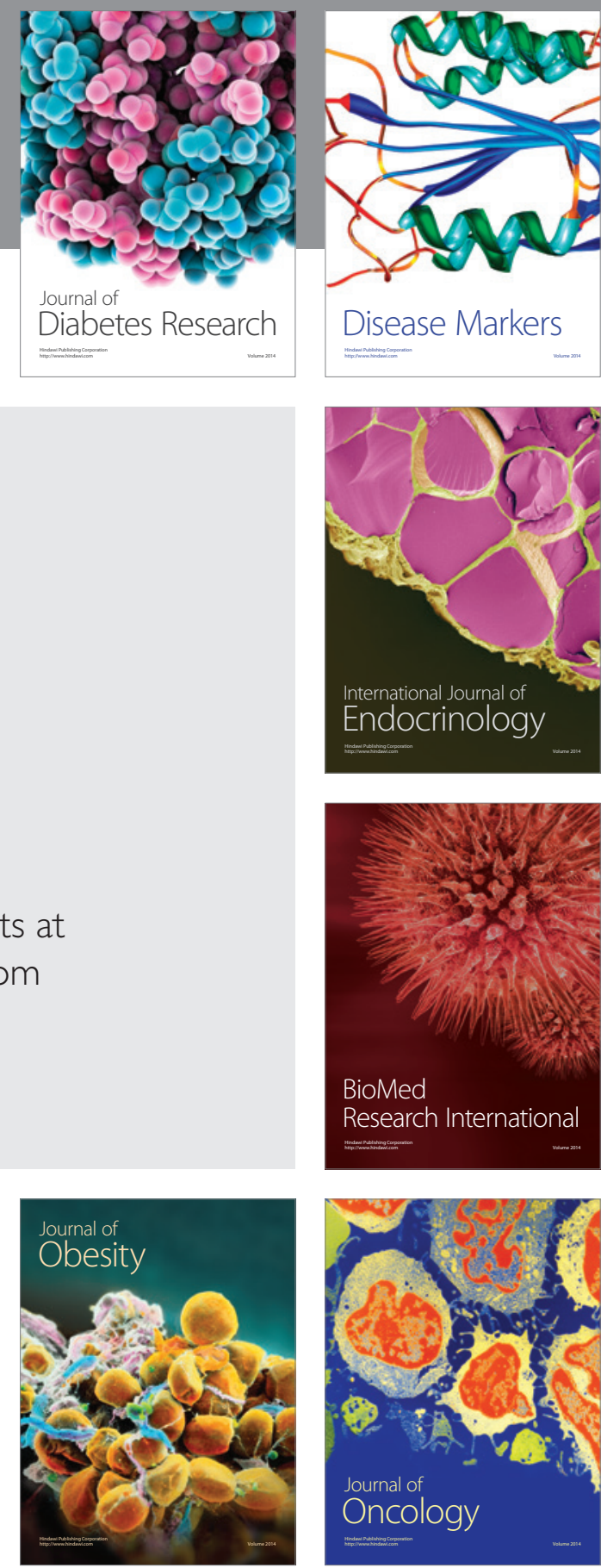

Disease Markers
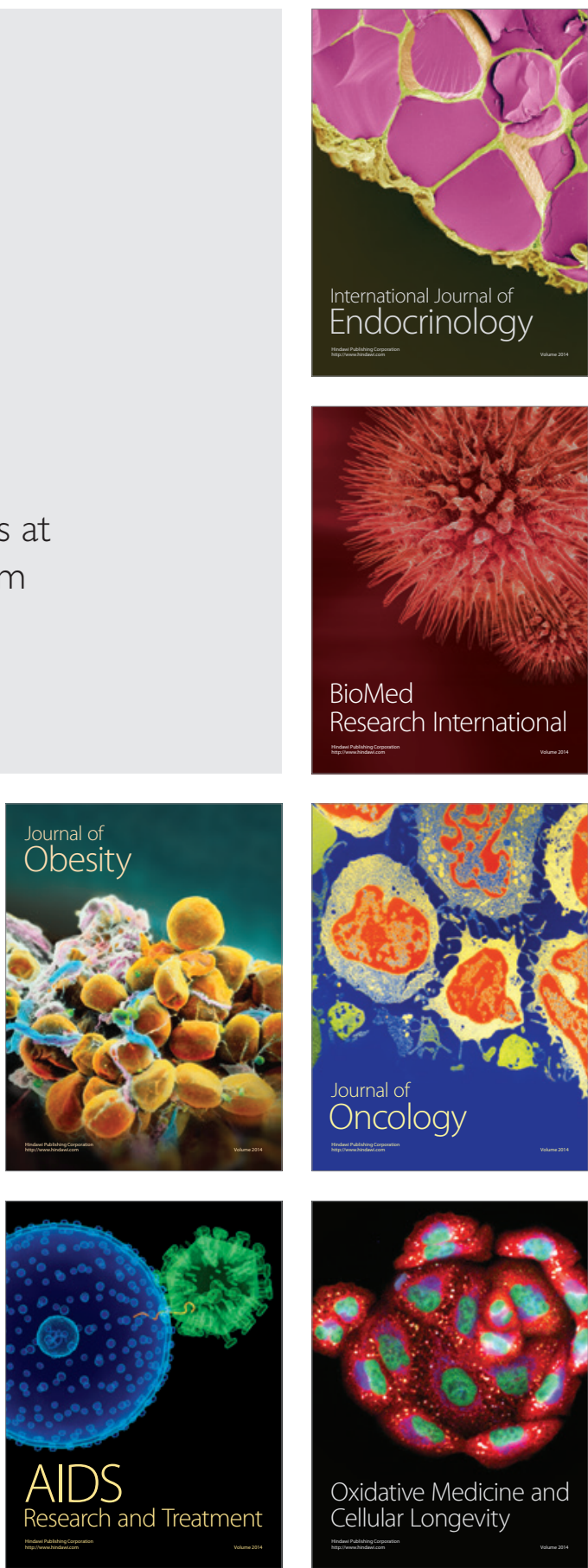